\title{
Advances in Biosensors Technology for Detection and Characterization of Extracellular Vesicles
}

\author{
Saif Mohammad Ishraq Bari ${ }^{1} \mathbb{D}$, Faria Binte Hossain ${ }^{2}$ and Gergana G. Nestorova ${ }^{3, *}$ \\ 1 Micro and Nanoscale Systems Engineering, Louisiana Tech University, Ruston, LA 71272, USA; \\ smi015@latech.edu \\ 2 Molecular Science and Nanotechnology, Louisiana Tech University, Ruston, LA 71272, USA; \\ fbh004@latech.edu \\ 3 School of Biological Sciences, Louisiana Tech University, Ruston, LA 71272, USA \\ * Correspondence: ggnestor@latech.edu
}

Citation: Ishraq Bari, S.M.; Hossain, F.B.; Nestorova, G.G. Advances in Biosensors Technology for Detection and Characterization of Extracellular Vesicles. Sensors 2021, 21, 7645 . https://doi.org/10.3390/s21227645

Academic Editor: Akio Kuroda

Received: 19 October 2021

Accepted: 15 November 2021

Published: 17 November 2021

Publisher's Note: MDPI stays neutral with regard to jurisdictional claims in published maps and institutional affiliations.

Copyright: (c) 2021 by the authors. Licensee MDPI, Basel, Switzerland. This article is an open access article distributed under the terms and conditions of the Creative Commons Attribution (CC BY) license (https:// creativecommons.org/licenses/by/ $4.0 /)$.

\begin{abstract}
Exosomes are extracellular vehicles (EVs) that encapsulate genomic and proteomic material from the cell of origin that can be used as biomarkers for non-invasive disease diagnostics in point of care settings. The efficient and accurate detection, quantification, and molecular profiling of exosomes are crucial for the accurate identification of disease biomarkers. Conventional isolation methods, while well-established, provide the co-purification of proteins and other types of EVs. Exosome purification, characterization, and OMICS analysis are performed separately, which increases the complexity, duration, and cost of the process. Due to these constraints, the point-of-care and personalized analysis of exosomes are limited in clinical settings. Lab-on-a-chip biosensing has enabled the integration of isolation and characterization processes in a single platform. The presented review discusses recent advancements in biosensing technology for the separation and detection of exosomes. Fluorescent, colorimetric, electrochemical, magnetic, and surface plasmon resonance technologies have been developed for the quantification of exosomes in biological fluids. Size-exclusion filtration, immunoaffinity, electroactive, and acoustic-fluid-based technologies were successfully applied for the on-chip isolation of exosomes. The advancement of biosensing technology for the detection of exosomes provides better sensitivity and a reduced signal-to-noise ratio. The key challenge for the integration of clinical settings remains the lack of capabilities for on-chip genomic and proteomic analysis.
\end{abstract}

Keywords: sensors; exosomes; lab-on-a-chip

\section{Introduction}

Extracellular vesicles (EV) play important role in cell-to-cell communication and serve as an important source of genomic and proteomic biomarkers for the early detection and diagnosis of diseases [1,2]. EVs are found in all biofluids, including blood, urine, saliva, synovial fluid, and cerebrospinal fluid, and encapsulate proteins, lipids, and nucleic acids from the cell of origin [3,4]. Depending on their biogenesis and structures, EVs are categorized as apoptotic bodies, microvesicles, and exosomes (Figure 1). Exosomes are the smallest type of EVs (40-160 nm) and are released via endocytic pathways [5]. They are considered to be a promising source of biomarkers for disease diagnosis, including cancer, diabetic cardiomyopathy, arthritis, asthma, and neurodegeneration, since their biological cargo reflects the pathophysiological condition of the host cell [6-11]. Exosomes are promising candidates as drug delivery vesicles due to their low immunogenic potential coupled with the effective protection of the nucleic acid and protein cargo from degradation. Nucleic acid and protein from the cell of origin are selectively sorted in the exosomes. The molecular cargo of the vesicle reflects the pathological condition of the parent cell and therefore provides a source of biomarkers for the early diagnosis of diseases [12]. Due to 
easy access to biofluids enriched in exosomes and high cell-specificity, exosomes can be used in liquid biopsy for early diagnosis.

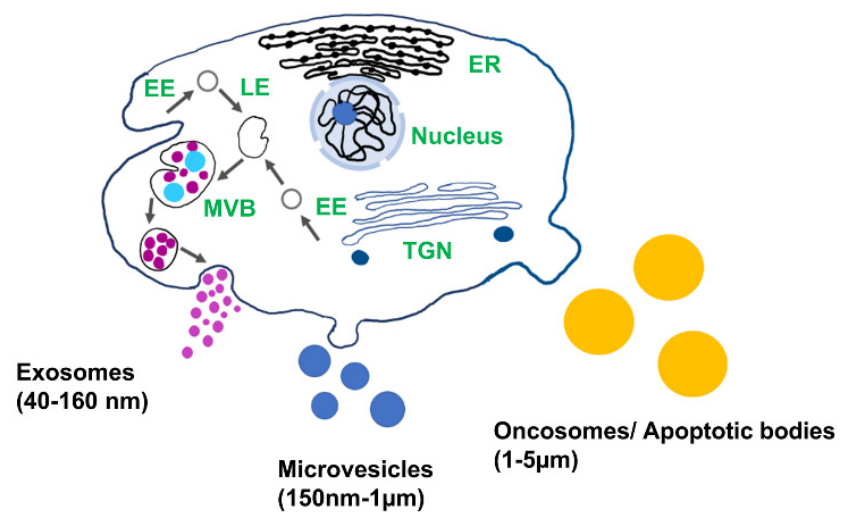

Figure 1. Schematic of different types of extracellular vesicles and their biogenesis: EE: early endosomes, LE: late endosomes, MVB: multivesicular body, TGN: trans-Golgi network, and ER: endoplasmic reticulum.

The protein contents in exosomes include transmembrane proteins, lysosome-derived membrane proteins, lactadherin, membrane-associated proteins, GTPases, heat shock proteins, lipid-related proteins, phospholipases, tetraspanins, and proteins associated with the multivesicular body (MVs) biogenesis [13-16]. Multiple studies suggest that the proteomic analysis of exosomes can facilitate the early detection of cancer, metabolic diseases, and neurological disorders $[17,18]$. Therefore, the isolation of a pure exosomal subpopulation from a biological fluid is crucially important to determine their pathophysiological functions. This review provides a detailed discussion of the advantages and barriers in conventional exosome sensing techniques and the most recent advancements and challenges in biosensors for the purification and on-chip detection of exosomes.

\section{Exosome's Biogenesis, Molecular Cargo, and Function}

The biogenesis of exosomes starts in early endosomes. Matured or late-endosomes move to the cytoplasm, change their tube-like shape into a spherical one, and form the multivesicular bodies (MVBs). Inward budding results in the progressive accumulation of intraluminal vesicles (ILVs) inside the MVB. The development of the multivesicular endosomes can follow either of the following pathways, as shown in Figure 2:

- MVBs fuse with lysosomes and degrade their content.

- MVBs fuse with the plasma membrane and release their content into the extracellular space.

For the first pathway, the MVBs are hydrolyzed by the lysosomes. When the MVBs fuse with the plasma membrane, the exosomes are released into the extracellular space [19]. Studies have indicated that the formation of ILVs and the process of exosome release are mediated by tetraspanins (CD9, CD63, CD81), glycan modification, and Rab guanosine triphosphatases (RAB 27A, RAB 27B, RAB 31, and RAB 11) $[1,11,20,21]$. The complex underlying biology of exosome formation and what factors govern the transition of the MVBs to the exocytic pathway or the degradative pathway remain to be further characterized [4].

Exosomes contain a diverse cargo that includes proteins, DNA, mRNA, non-coding RNA, tRNA, DNA, and lipids [21]. The proteomic content comprises exosomal marker proteins (TSG101, HSP90 $\beta$, HSC70, Alix), tetraspanins (CD9, CD63, CD81, CD82), and cell-specific proteins (ex. EpCAM) [21,22]. The exosomal marker proteins are found in the exosomes regardless of the cell of origin $[23,24]$. The transmembrane proteins belong to the tetraspanin family and are enriched in the exosomes [25]. However, the tetraspanin proteins are also available in MVs and apoptotic bodies [26], as are the EVscontain miRNA, 
mRNA, tRNA, nucleic acids, DNA, and lipids [27-33]. The lipid contents in exosomes include saturated fatty acids, cholesterol, sphingomyelin, and phosphatidylserine [34].

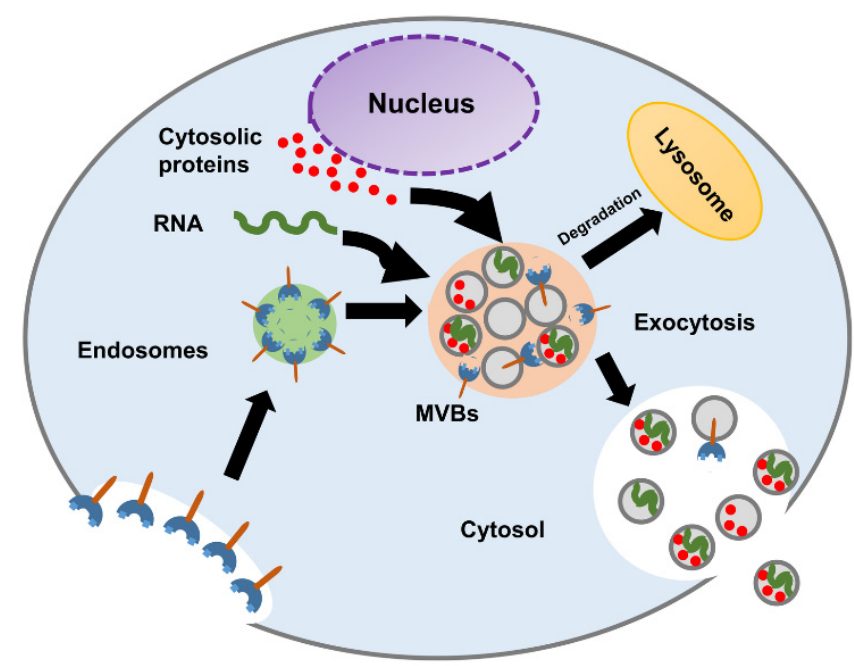

Figure 2. Schematic diagram of exosome biogenesis and molecular composition.

EVs mediate cell-to-cell communication via the transfer of genomic or proteomic content from the donor to the recipient cell [35]. The cell can alter the exosomal cargo in response to the changes in the extracellular environment. Malignant cells secrete EVs that facilitate metastasis, and EVs influence the immune response [36]. Due to their involvement in pathological processes exosomes, can provide diagnostic biomarkers and deliver therapeutic agents. The further development of exosome-based diagnostic and drug delivery platforms requires rapid and specific isolation techniques. For example, the cerebrospinal fluid contains EVs that carry vital information about the function of the central nervous system, and methods for purification that can noninvasively access and preconcentrate the vesicles could provide technology for the early diagnosis of neurological disorders [37]. Therefore, the development of a highly selective method for EV separation and characterization is important for the accurate identification of biomarkers and the selective drugs or nucleic acid delivery to the target cells.

\section{Conventional Methods for Isolation and Detection of Exosomes}

The main methods for exosome isolation are based on the properties of the vesicles such as size, protein surface markers, and density. These include ultracentrifugation [38], immunoaffinity-based techniques [39-42], size-exclusion chromatography [43,44], and polymer-based precipitation [45]. The advantages and disadvantages of each technique are presented in Table 1. 
Table 1. Summary of a comparative study of existing conventional exosome isolation techniques.

\begin{tabular}{|c|c|c|c|c|c|c|c|}
\hline \multirow{2}{*}{ Isolation Technique } & \multirow{2}{*}{ Isolation Principle } & \multicolumn{3}{|c|}{ Appraisal Parameters } & \multirow{2}{*}{ Advantages } & \multirow{2}{*}{ Disadvantages } & \multirow{2}{*}{ References } \\
\hline & & Time & Yield & Purity & & & \\
\hline Ultracentrifugation & Density-based & * & * & $* *$ & The gold standard & $\begin{array}{l}\text { Time-consuming; low yield; } \\
\text { moderate purity; }\end{array}$ & {$[38,46]$} \\
\hline Immunoaffinity-capture & Affinity-based & ** & $* *$ & $* * *$ & Highly specific and pure & $\begin{array}{l}\text { Expensive; strict } \mathrm{pH} \text { condition; } \\
\text { constrained use }\end{array}$ & {$[40,41]$} \\
\hline Size-exclusion chromatography & Vesicles Size & $* *$ & $* *$ & $* *$ & Simple, rapid, moderate yield & Poor specificity; scaling problems & {$[44,47,48]$} \\
\hline Ultrafiltration & Molecular weight and size-based & $* *$ & * & $* *$ & Simple, no specific instrument & $\begin{array}{l}\text { Clogging; low yield, low specificity, } \\
\text { time-consuming }\end{array}$ & [50-52] \\
\hline
\end{tabular}

Appraisal parameters are categorized by ${ }^{* * *},{ }^{* *}$, and ${ }^{*}$ imply very good, moderate, and poor performances, respectively. 
The conventional methods for the detection and characterization of exosomes include flow cytometry, ELISA, tunable resistive pulse sensing (TRPS), dynamic light scattering (DLS), and nanoparticle tracking analysis (NTA). Flow cytometry is based on intersecting a laser beam with fluorescence-labeled exosomal particles and provides a high throughput multiplex analysis of surface markers [53]. Despite these advantages, the technique provides low sensitivity and resolution [54]. ELISA is based on antibody-mediated detection and the quantification of exosomal particles and is one of the most commonly used techniques for the detection of EVs [55]. Digital PCR provides excellent sensitivity for a low volume of samples $[56,57]$. TRPS is based on the principle that the movement of the non-conductive components in an electrolyte solution can cause a change in the electrical impedance relative to the particle concentration, size, and surface charge [58]. TRPS provides accuracy in determining the size, concentration, and surface charge of exosomes $[59,60]$. Both DLS and NTA assess the Brownian motion of the exosomes to measure the size and concentration of the nanoparticles [61]. While the DLS method analyzes the relative change in the intensity of the scattered light induced by the Brownian motion of the suspended nanoparticles, e.g., exosomes, NTA implements the Stokes-Einstein equation to calculate the hydrodynamic diameter of the nano components [62,63]. Due to their capabilities of discerning nanoparticles of various sizes ranging from 1 to $1000 \mathrm{~nm}$, both DLS and NTA have been widely used for the detection and quantification of exosomes. However, the accuracy of the results can be reduced for samples that are prone to aggregation [61]. While all of these techniques are successfully used in research settings, the requirements of sophisticated instruments, the implementation of separate techniques for isolation and analysis, and the interference of other types of EVs create challenges for application in clinical settings [64].

\section{Sensors for Detection and Molecular Characterization of Exosomes}

Tremendous progress has been made in the area of biosensor technology for the detection, quantification, and analysis of exosomes. Lab-on-a-chip biosensing offers multiple advantages over the conventional techniques that include low sample volume input, multiplexing, cost-effectiveness, and precise fluidic control $[65,66]$. Microfluidics provides single sample input-output, reduced cross-contamination, more efficient isolation, and increased sensitivity of quantification for applications in clinical settings [67]. To simplify and automate the purification and characterization of exosomes and other EVs, the conventional methods discussed in the previous section have been integrated with the lab-on-a-chip platforms. The biophysical characterization and separation of the heterogeneous exosome population have been successfully performed in microfluidic devices using the asymmetric flow field-flow fraction (AF4). The EVs were separated based on their density and hydrodynamic properties [68]. Nanoporous membranes were integrated into a microdevice (ExoTIC) that enabled the efficient, size-dependent separation of EV for subsequent molecular analysis. This platform provides a higher yield than conventional ultracentrifugation and polymer precipitation techniques [69]. An integrated centrifugal microfluidic platform enabled the efficient enrichment (greater than 95\%) of EV and the subsequent on-chip ELISA detection of surface markers [70]. A $\mathrm{ZnO}$ nanowire-functionalized PDMS microfluidic platform was successfully used for the enrichment of urine-derived EVs [71]. Size-selective EV separation was demonstrated in a microchip (ExoSMP) by combining membrane filtration and electrophoretic force. Separation of different subgroups can be performed by altering the pore size of the membrane [72]. The following sections discuss the most recent advances in biosensor technology for EV detection and molecular characterization.

\subsection{Fluorescence-Based Sensors}

Multiple researchers have reported upon the fluorescent-labeling of exosomes combined with different isolation approaches. Kanwar et al. reported the on-chip exosome isolation and analysis platform, ExoChip, which employed the CD63 antibody-mediated 
isolation of exosomes from blood serum (Figure 3). Subsequently, the captured exosomes were stained with $\mathrm{DiO}$ fluorescent dye followed by quantification using a plate reader [73].

(i)
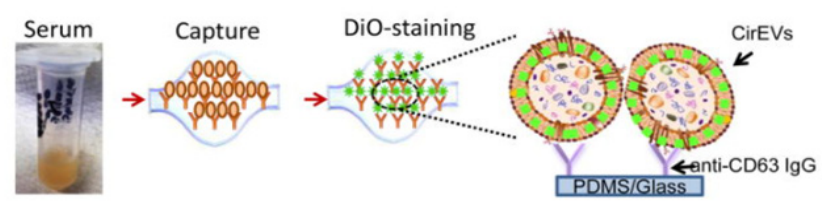

(ii)

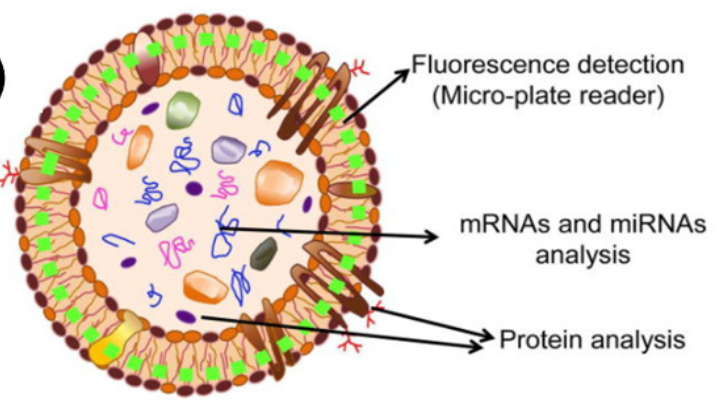

(iii)

(iv)
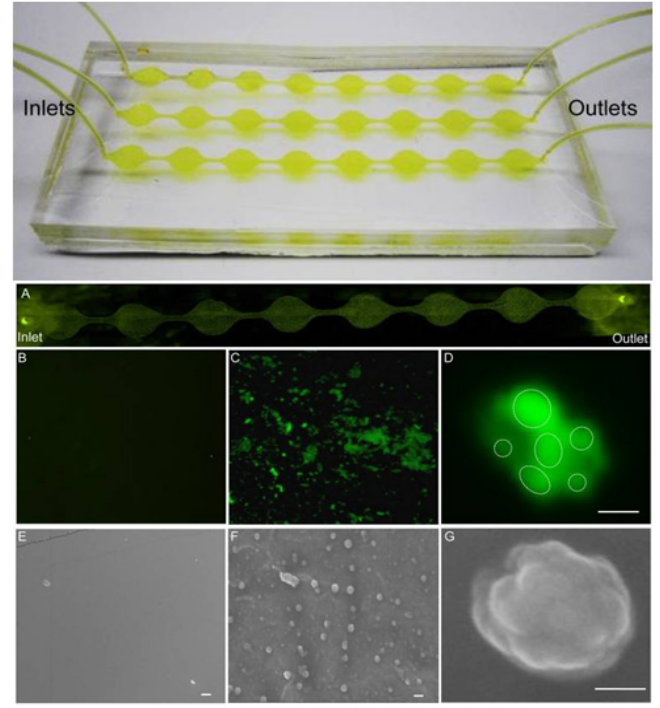

Figure 3. (i) Schematics of CD63 enrichment and membrane-specific DiO staining of exosomes using ExoChip platform. (ii) The fluorescent intensity of the $\mathrm{DiO}$ stained exosomes is measured using a fluorescent plate reader, while the genomic and the proteomic content can be characterized using Western blot or RT-qPCR analysis. (iii) Model of PDMS-based ExoChip. The device consists of multiple, connected circular chambers with a diameter of $5 \mathrm{~mm}$ and $100 \mu \mathrm{m}$ in height. (iv) Microscopy visualization of the exosomes and the ExoChip channel. (A) Fluorescence image of DiO stained exosomes immobilized to the lower surface of the device. Fluorescent image of the control chamber (B) and anti-CD63 coated chamber with captured exosomes (C), 400×. (D) A confocal microscopic image of a cluster of exosomes (bar = $2 \mu \mathrm{m})$. Electron micrograph (EM) images of control ExoChip (E) and anti-CD63 functionalized ExoChip (F) (bar = $500 \mathrm{~nm})$. (G) EM image of a cluster of exosomes (bar $=100 \mathrm{~nm}$ ). Reprinted (adapted) with permission from Kanwar et al., 2014. Copyright 2014, Royal Society of Chemistry.

A homogeneous magneto-fluorescent exosome (hMFEX) nanosensor has been developed for rapid tumor-derived exosomes analysis [74]. This platform was able to detect tumor-derived exosomes with high specificity and sensitivity. The limit of detection was $6.56 \times 10^{4}$ particles $\mu \mathrm{L}^{-1}$, demonstrating the potential clinical diagnostic efficacy [74]. Quantification and differentiation between a normal and metastatic sentinel lymph node (SLN)-derived exosomes captured using fluorescent silicon nanoparticles-based exosome probes (SiNPs@EXO) have successfully been demonstrated [75]. To study the exosomes derived from mouse breast cancer (4T1) and human embryonic kidney (HEK293T) cells, 1,8-napthalimide fluorophores were used. Exosomes derived from 4T1 cells showed higher fluoresce intensity than the negative control (HEK293T). Fluorescence analysis depicted that the fluorescence signals in metastatic SLNs reached a peak within $30 \mathrm{~min}$ and stayed for up to $3 \mathrm{~h}$, whereas normal SLNs attained the peak in about an hour followed by a sudden decrease in the signal [75]. This integrated approach can be used for predicting lymphatic metastasis via the detection of SLN-derived exosomes.

\subsection{Colorimetric Sensors}

On-chip colorimetric detection has been employed by many groups to quantify and characterize exosomes. Vaidyanathan et al. reported a multiplexed microfluidic platform with antibody-functionalized electrodes specific for capturing exosomes. The approach is based on the alternating current electrohydrodynamic (ac-EHD)-induced surface shear force (also known as nano shearing) that stimulates the fluid flow within a few nanometers of the electrodes. Absorbance measurement of the colorimetric solution was used to detect and quantify exosomes with high specificity. This platform showed superior sensitivity 
(2760 exosomes $\mu \mathrm{L}^{-1}$ ) compared to other fluid dynamic-based approaches [76]. A sensitive and selective colorimetric aptasensor was successfully implemented for the detection of cancer-derived exosomes. The chromogenic signal was produced by the polymerization of horseradish peroxidase (HRP)-accelerated dopamine (DA) and the in situ deposition of polydopamine (PDA) [77]. The target exosomes were first isolated by latex beads followed by bio-recognition using a specific CD63 aptamer, which was conjugated to horseradish peroxidase (HRP) through biotin-streptavidin binding [77] (Figure 4). Colorimetric detection was completed in 10 min via enzymatic catalysis, which produced dark-colored polydopamine (PDA) from colorless dopamine (DA). The color depth correlated to the CD63 amount, and the reported limit of detection (LOD) was $7.7 \times 10^{3}$ particle $\mathrm{mL}^{-1}$, increasing the LOD by $3-5$ orders of magnitude from conventional Dot-blot methods [77].

A

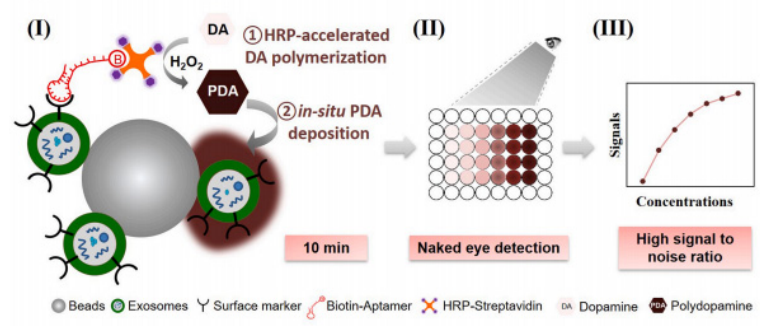

B
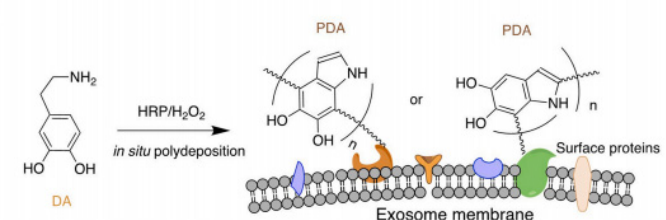

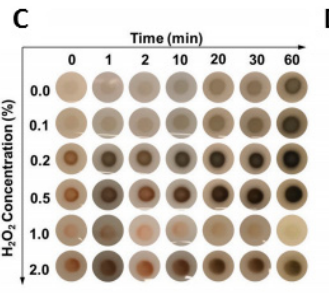

D

E

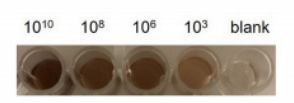

$\mathbf{F}$
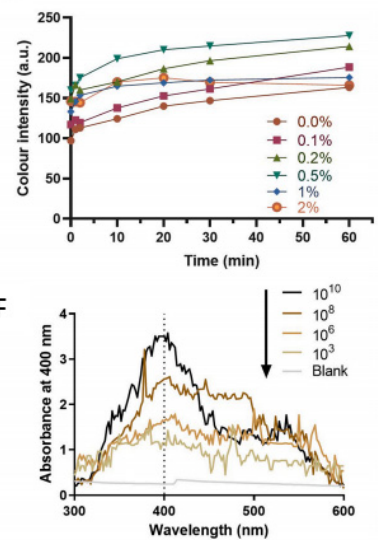

Figure 4. (A) (I) Exosomes were anchored on sulfate/latex beads by aldimine condensation followed by binding to a CD63-specific aptamer conjugated to biotin. Incubation with streptavidin-conjugated HRP converted colorless dopamine (DA) into brown-black colored polydopamine (PDA). (II) The color change is proportional to exosome concentrations. (III) The absorbance signals of the reaction can also be measured at $400 \mathrm{~nm}$. (B) Schematics of the deposition of PDA onto the exosome membrane. (C) The color change of PDA deposition at the target site of $\mathrm{HRP}$ at different $\mathrm{H}_{2} \mathrm{O}_{2}$ concentrations. (D) The change in the color intensity is a function of time and $\mathrm{H}_{2} \mathrm{O}_{2}$ concentration. (E) Images of exosome samples after color development in the ExoAptaSensor. (F) Absorbance peak at $400 \mathrm{~nm}$ correlates with exosome concentrations. Reprinted from Development of a simple, sensitive, and selective colorimetric aptasensor for the detection of cancer-derived exosomes, Volume 169, Xu et al., 2020a, Page No. 112576, Copyright 2020, with permission from Elsevier.

A highly sensitive plasmonic colorimetric biosensor for exosome quantification based on a two-step sensing technique was reported. The technique employed an exosomeinduced competitive reaction and etching of gold nanobipyramid@ $\mathrm{MnO}_{2}$ nanosheet nanostructures (Au NBP@ $\mathrm{MnO}_{2} \mathrm{NSs}$ ) [78]. A competitive reaction induced by exosomes translated the signal of exosomes into the amount of alkaline phosphatase, which simplified the experimental process and amplified the signal. The refractive index of Au NBPs was increased via the etching of the Au NBP@MnO $\mathrm{NSs}_{2}$ by ascorbic acid. The combination of excellent refraction and signal amplification provided a limit of detection of $1.35 \times 10^{2}$ particles $\mu \mathrm{L}^{-1}$, providing superior exosome detection sensitivity than previously reported colorimetric methods [78].

\subsection{Magnetic Sensors}

Because of their small size, exosomes interfere with the detection capabilities of traditional nuclear magnetic resonance (NMR). Micro-nuclear magnetic resonance ( $\mu N M R$ ) was developed for capturing small particles such as exosomes [79]. Shao et al. developed a microfluidic-based $\mu$ NMR device for the detection and differentiation of multiforme glioblastoma EVs from non-tumor host cell-derived EVs. The vesicles were isolated using immunomagnetic nanoparticles (IMNPs) followed by the filtration of the super magnetic 
IMNP-exosome complexes. This approach resulted in the excellent reproducibility and accuracy of EV quantification and protein characterization [80]. Sancho-Albero et al. reported a continuous-flow microfluidic device for the isolation and analysis of whole blood exosomes derived from pancreatic cancer (PC) patients via CD9-mediated magnetic capture (Figure 5). The specificity of the technique was validated via the ELISA analysis of exosomal Ca19-9 levels in PC patients and healthy individuals. This platform can be used for the early detection and assessment of PC progression using exosome analysis [81].

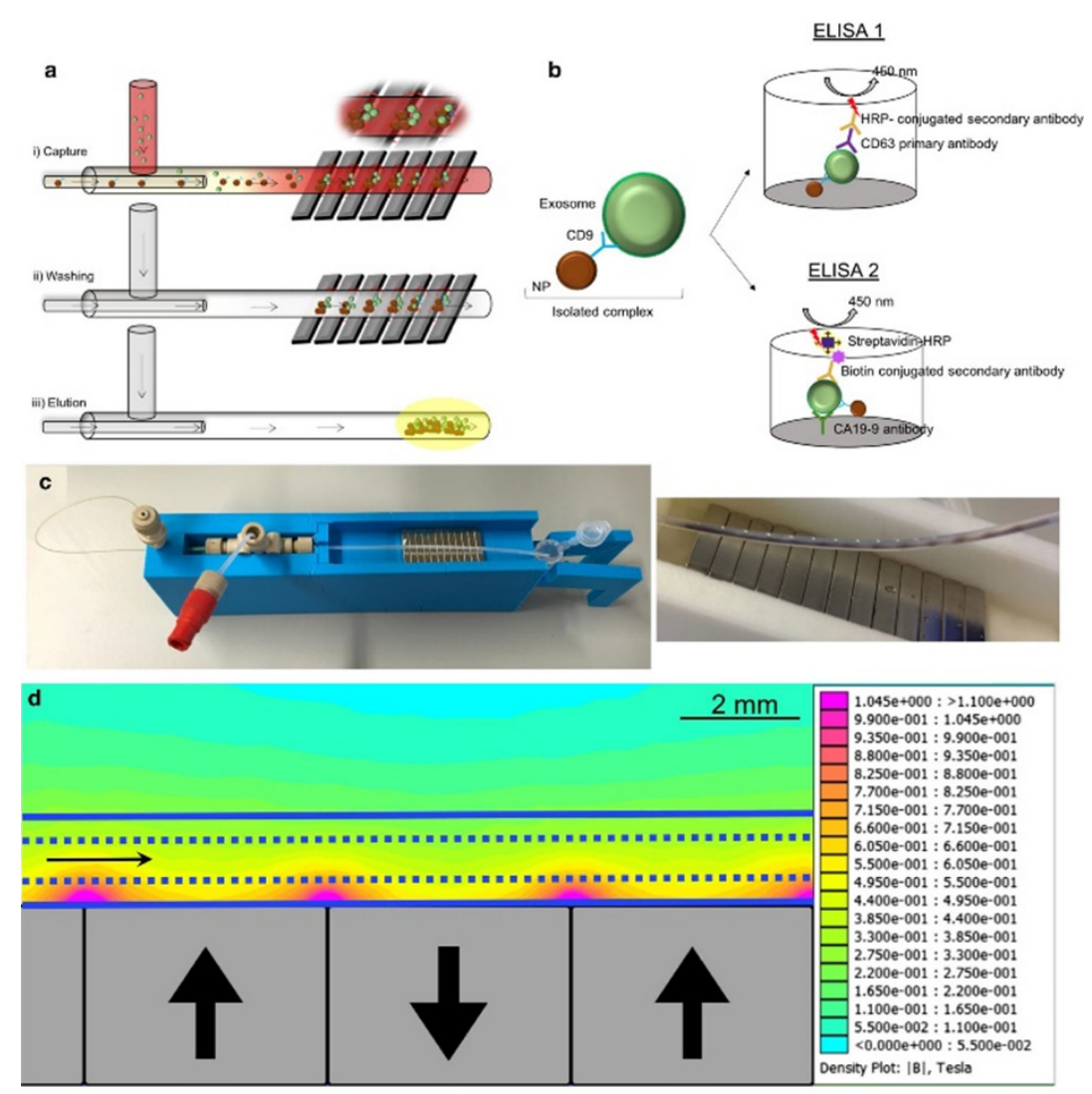

Figure 5. (a) Exosomes are captured by antibody functionalized nanoparticles $\left(\mathrm{Fe}_{3} \mathrm{O}_{4}\right.$-EDC-NHSNP: anti CD9). (b) ELISA was performed to quantify exosomes and to measure CA19-9 levels. (c) Experimental setup and capture of the magnetic particles in the channel. (d) Simulation of the magnetic gradient. Reproduced with permission from Sancho-Albero et al., 2020 under Creative Commons Attribution License (CC BY 4.0), Copyright 2020, Springer Nature.

\subsection{Surface Plasmon Resonance (SPR) Sensors}

Surface plasmon resonance (SPR) is defined as the resonant oscillation of the electrons stimulated by the incident light at the interface between a negative and a positive dielectric constant material. This oscillation enables the sensitive detection of change in the boundary conditions, which is employed for the detection of adsorption of biomolecules to the surface $[82,83]$. Microfluidic-based SPR is an emerging method of exosome isolation due to its cost-effectiveness, portability, and the ability of fast and label-free detection. An on-chip SPR sensor was developed for the isolation and quantification of tumor-derived exosomes. The gold surface was functionalized with antibodies specific to exosome surface markers, and the refractive index changed upon the binding of the vesicles to the capture antibodies. The antibody array enabled the multiplex analysis of the surface markers in a single sample (Figure 6) [84]. 


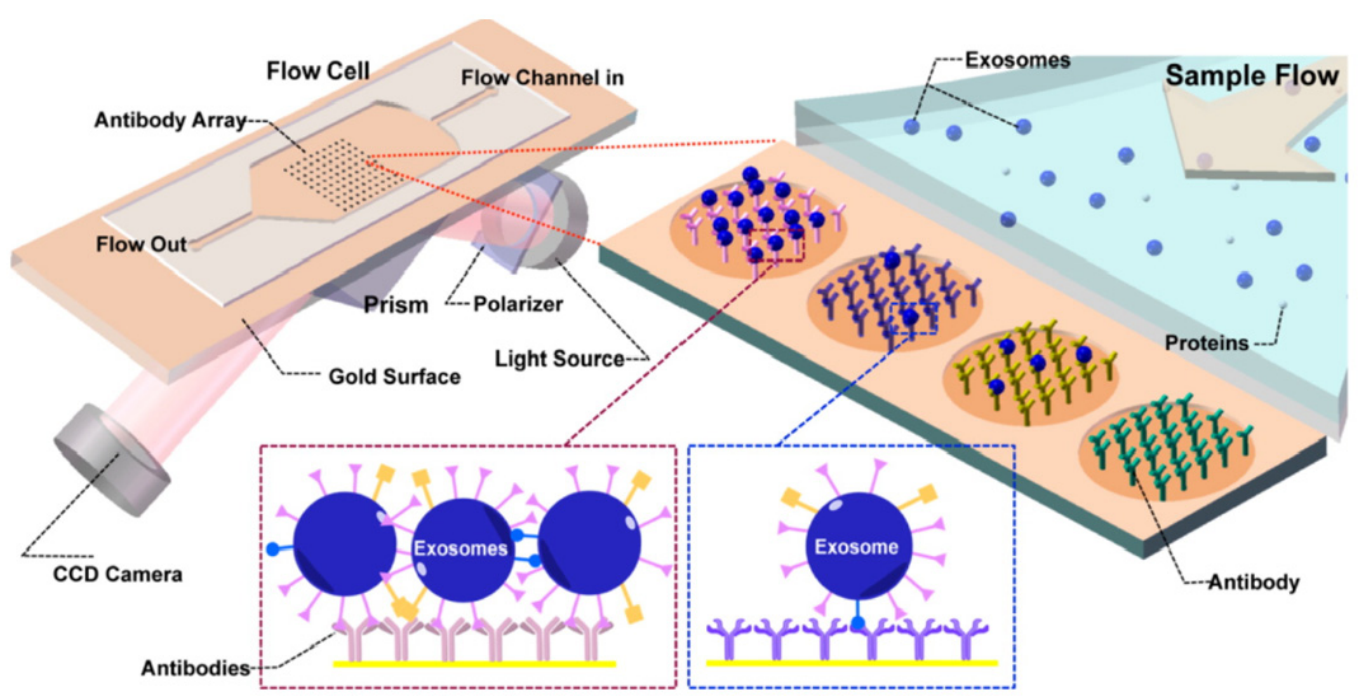

Figure 6. Principle of operation of SPR sensor incorporating an antibody array specific to exosomes transmembrane proteins. The binding of the exosomes causes a change in the refractive index of the laser that is detected by the CCD camera. Reproduced with permission from Zhu et al., 2014 (article link: https:/ / pubs.acs.org/doi/10.1021/ac5023056 (accessed on 30 September 2021), Copyright 2014, American Chemical Society. Any future use of this content is subjected to permission from ACS Publications.

W. Chen et al. reported a label-free real-time surface plasmon resonance imaging (SPRi) biosensor based on the hydrogel-gold nanoparticles supramolecular sphere (H-AuNPs). This approach was successfully used for the detection and quantification of prostate cancer cell-derived exosomes. The localized surface plasmon resonance of AuNPs and the signal amplification effect of the mass cumulative multi-layered porous hydrogels enhanced the sensitivity of the platform. The sensor has a limit of detection of $10^{5}$ particles $\mathrm{mL}^{-1}$ [85]. The SPRi-based quantification correlated with the tumor-derived prostate-specific antigen (t-PSA) values measured via clinically validated chemiluminescence immunosensors. The microfluidic biosensor was successfully employed for the analysis of human serum samples and could have future applications in clinical settings.

\subsection{Electrochemical Sensors}

Electrochemical sensors measure the electric current generated from oxidative or reductive reactions. This approach can be easily integrated with a microfluidic platform and enables highly sensitive biomolecular detection [86]. Zhou et al. reported an aptamer-based electrochemical biosensor for the quantitative detection and analysis of exosomes in a microfluidic device. The aptamers specific to the exosome-specific tetraspanin protein, CD63, were immobilized on gold electrodes. The concentration of the exosomes was inversely proportional to the signal generated due to the binding of methylene blue-labeled probe strand and the CD63 aptamer. Signal output decreased in the presence of the exosomes, as they displaced the probe strands. This reported biosensor was able to detect $10^{6}$ per $\mathrm{mL}^{-1}$ exosomes, representing a 100-fold improvement in sensitivity over commercial ELISA assays [87]. A detachable microfluidic device with an integrated electrochemical aptasensor was successfully used for the detection and genomic characterization of breast cancerderived exosomes (Figure 7). An aptamer specific to epithelial cell adhesion molecules was immobilized onto the gold-plated electrode, and a microfluidic vortexer was integrated using 3D printed magnetic housing. The hydrodynamically generated transverse flow increased the rate of collisions between the exosomes and sensing surface. The reported platform demonstrated ultra-high sensitivity (17 exosomes $\left.\mu \mathrm{L}^{-1}\right)$ over a wide dynamic range $\left(1 \times 10^{2}\right.$ to $\left.1 \times 10^{9}\right)$ exosomes $\mu \mathrm{L}^{-1}[88]$. 

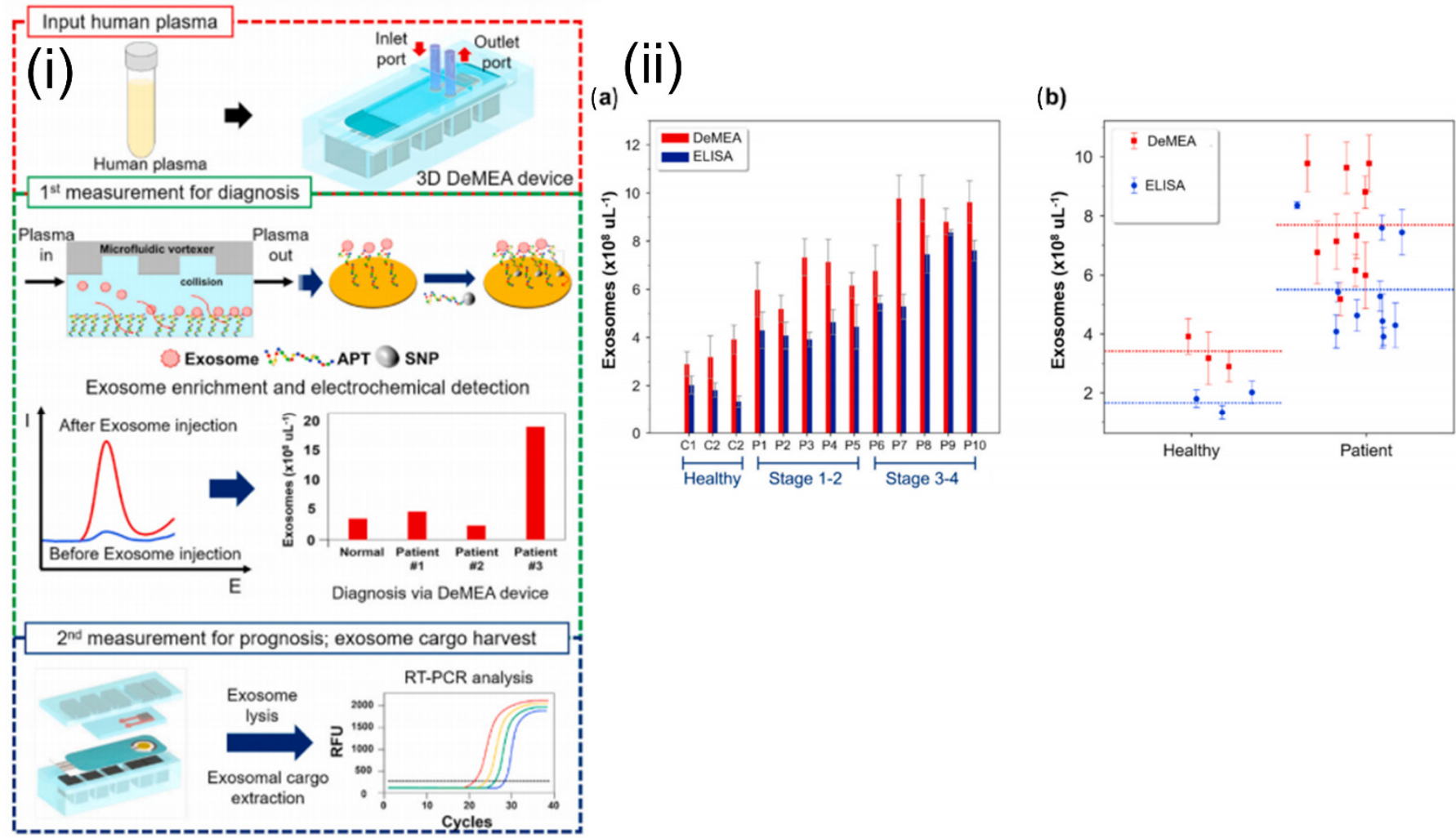

Figure 7. (i) Schematics and experimental workflow of the microfluidic platform with electrochemical aptasensor (DeMFA) for the quantification and cargo analysis of exosomes. (ii) DeMEA and ELISA quantification of exosomes derived from plasma samples of healthy and MCF-7 cancer cells represented in: (a) bar graph, $(\mathbf{b})$ scatter graph $(\mathrm{n}=3)$. Reprinted from Detachable microfluidic device implemented with electrochemical aptasensor (DeMEA) for sequential analysis of cancerous exosomes, Volume 169, Kashefi-Kheyrabadi et al., 2020, Page No. 112622, Copyright 2020, with permission from Elsevier.

\subsection{Immunoaffinity Sensors}

Immunoaffinity-based approaches are employed for the isolation and quantification of exosomes that express specific surface markers. The specificity of the antibody and the degree of nonspecific binding of the exosomes to the surface affect the purity of the exosomal subpopulation. The antibody-based isolation of exosomes using the antiCD63 antibody was successfully performed on a microfluidic device with herringbone groves that ensured efficient mixing, manipulation, and separation of the fluid and the vesicles [89]. Kanwar et al. developed an anti-CD63 antibody functionalized PDMS microfluidic chip for the isolation of exosomes from serum samples [73]. A glass-PDMS device coated with graphene oxide and polydopamine was employed for the selective capture of CD81 expressing exosomes from plasma samples (Figure 8). This nanostructured interface improved the efficiency and reduced nonspecific binding to the surface of the device while providing a $4 \log$ dynamic range of detection. The platform was successfully employed for the detection and discrimination of exosomes derived from ovarian cancer patients and healthy individuals using $2 \mu \mathrm{L}$ of serum [90]. Zhang et al. developed a herringbone mixerbased microfluidic chip that was able to directly separate exosomes from plasma using an immunoaffinity-based approach. This method enabled the successful enrichment of pancreatic cancer expressing Glypican-1 exosome subpopulations with 75\% efficiency [91]. Recently, another research group demonstrated the feasibility of a solid-phase, microprobebased technology for CD63-specific exosome purification that can further be integrated with a microfluidic platform for high-throughput and integrated omics analysis [42]. The ExoPRIME tool provides a Precise, Rapid, Inexpensive, Mild (non-invasive), and Efficient (i.e., PRIME) alternative for exosome isolation and analysis from both conditioned astrocyte media (CAM) and enriched exosome suspension (EXO). The results indicated that the 
reduced temperature with extended incubation times ensured high probe loading capacity ( $24 \times 10^{6}$ exosomes per microprobe). The probe $(3 \mathrm{~mm} \times 130 \mu \mathrm{m})$ captured a sufficient number of vesicles for subsequent genomic and proteomic analysis. The RNA capture efficiency was $0.54 \mathrm{ng}_{\text {probe }}^{-1}$ and $0.30 \mathrm{ng}_{\text {probe }}^{-1}$, respectively, for the EXO and CAM samples. The reported protein loading capacity was $940 \mathrm{ng}_{\text {probe }}^{-1}$ and $728 \mathrm{ng} \mathrm{probe}^{-1}$, respectively, for the EXO and CAM samples [42]. The same research group has also designed and mathematically identified the optimal design parameters of a microfluidic cell co-culture device with a pneumatically controlled valve that can be integrated with the ExoPRIME capture method for genomic and transcriptomic analysis of exosomes derived from the central nervous system and astrocytes [92].
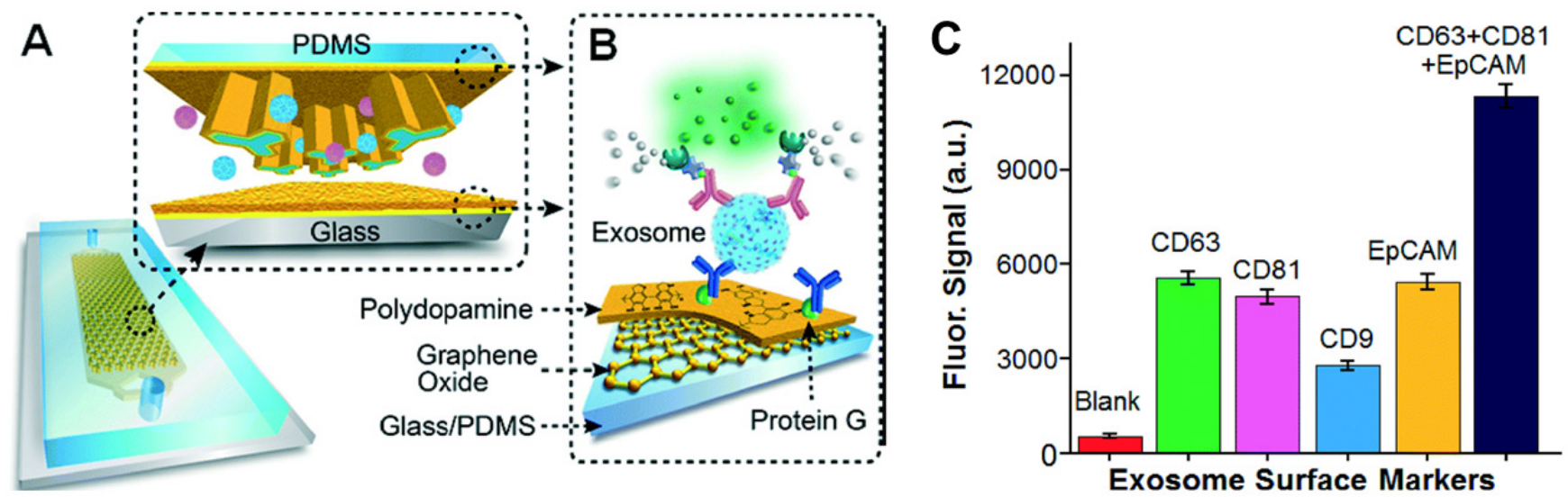

Figure 8. (A) Schematics of microfluidics platform based on graphene oxide/polydopamine nano-interface (nano-IMEX) for exosome immunocapture; (B) detection of exosomes surface markers via sandwiched ELISA. (C) Exosome surface marker profiling of COLO-1 cell exosomes $\left(10^{6} \mu \mathrm{L}^{-1}\right)$ captured by CD81 mAb. Reproduced with permission from Zhang et al., 2016 under Creative Commons Attribution Non-Commercial 3.0 Unported License, Copyright 2016, Royal Society of Chemistry.

A summary of the lab-on-a-chip methods used for the isolation of exosomes is presented in the following Table 2:

Table 2. Summary of the on-chip EVs detection techniques and reported limits of detection.

\begin{tabular}{|c|c|c|c|}
\hline Sensor Type & Isolation Principle & Minimum Detection Limit & References \\
\hline Fluorescence & Quantification of fluorescence signal & $6.56 \times 10^{7} \mathrm{EVs} \mathrm{mL}^{-1}$ & {$[74]$} \\
\hline Colorimetric & Absorbance measurement of the colorimetric solution & $1.35 \times 10^{5} \mathrm{EVs} \mathrm{mL}^{-1}$ & [78] \\
\hline Magnetic & Nuclear magnetic resonance & $4.39 \times 10^{3} \mathrm{EVs} \mathrm{mL}^{-1}$ & [93] \\
\hline $\begin{array}{l}\text { Surface Plasmon } \\
\text { Resonance (SPR) }\end{array}$ & $\begin{array}{l}\text { Resonant oscillation of the electrons stimulated by the } \\
\text { incident light at the interface between a negative and a } \\
\text { positive dielectric constant material }\end{array}$ & $10^{5} \mathrm{EVs} \mathrm{mL}^{-1}$ & [85] \\
\hline Electrochemical & $\begin{array}{l}\text { Measurement of the electric current caused by the } \\
\text { oxidation or reduction reactions }\end{array}$ & $10^{6} \mathrm{EVs} \mathrm{mL}^{-1}$ & [87] \\
\hline Immunoaffinity & Affinity-based isolation & $24 \times 10^{6} \mathrm{EVs} \mathrm{mL}^{-1}$ & [42] \\
\hline
\end{tabular}

\section{Conclusions}

This article summarizes the biological functions of exosomes and their functional roles as disease biomarkers and prospective applications for point-of-care diagnostics. The conventional isolation and detection methods and the recent advances in sensor technology have been discussed, including their advantages and disadvantages. Although on-chip biosensing provides a rapid and more accurate quantification and analysis of exosomes from various biofluids compared to conventional techniques, the challenge of 
integration with high-throughput genomic and proteomic instrumentation remains. Due to the heterogeneous nature of EVs, it is often very difficult to obtain highly pure exosomes that result in lowering the accuracy of the detected biomarkers. The preparation of a pure EV population is an important starting point in the development of point-of-care tests for disease diagnosis and for the development of novel therapeutic agents. Because of the ongoing research and development efforts to integrate all of the sample processing and analysis steps in a single platform, it can be anticipated that in the future, exosome isolation and detection could be performed in a single integrated microfluidic device for the application in point-of-care diagnostics.

Author Contributions: G.G.N.: conceptualization, writing-review and editing; S.M.I.B.: conceptualization, writing —original draft; F.B.H.: writing-original draft. All authors have read and agreed to the published version of the manuscript.

Funding: This research was funded by the Louisiana Board of Regents, grant number LEQSF (201821)-RD-A-27.

Institutional Review Board Statement: Not applicable.

Informed Consent Statement: Not applicable.

Data Availability Statement: Not applicable.

Conflicts of Interest: The authors declare no conflict of interest.

\section{References}

1. Colombo, M.; Moita, C.; van Niel, G.; Kowal, J.; Vigneron, J.; Benaroch, P.; Manel, N.; Moita, L.F.; Théry, C.; Raposo, G. Analysis of ESCRT functions in exosome biogenesis, composition and secretion highlights the heterogeneity of extracellular vesicles. J. Cell Sci. 2013, 126, 5553-5565. [CrossRef]

2. Katsuda, T.; Kosaka, N.; Ochiya, T. The roles of extracellular vesicles in cancer biology: Toward the development of novel cancer biomarkers. Proteomics 2014, 14, 412-425. [CrossRef] [PubMed]

3. EL Andaloussi, S.; Mäger, I.; Breakefield, X.O.; Wood, M.J.A. Extracellular vesicles: Biology and emerging therapeutic opportunities. Nat. Rev. Drug Discov. 2013, 12, 347-357. [CrossRef] [PubMed]

4. Margolis, L.; Sadovsky, Y. The biology of extracellular vesicles: The known unknowns. PLoS Biol. 2019, 17, e3000363. [CrossRef] [PubMed]

5. Szabo, G.; Momen-Heravi, F. Extracellular Vesicles and Exosomes. In The Liver; Wiley: Hoboken, NJ, USA, $2020 ;$ pp. $1022-1027$.

6. LeBleu, V.S.; Kalluri, R. Exosomes as a Multicomponent Biomarker Platform in Cancer. Trends Cancer 2020, 6, 767-774. [CrossRef]

7. Pang, H.; Luo, S.; Xiao, Y.; Xia, Y.; Li, X.; Huang, G.; Xie, Z.; Zhou, Z. Emerging Roles of Exosomes in T1DM. Front. Immunol. 2020, 11, 3099. [CrossRef]

8. Hejrati, A.; Hasani, B.; Esmaili, M.; Bashash, D.; Tavakolinia, N.; Zafari, P. Role of exosome in autoimmunity, with a particular emphasis on rheumatoid arthritis. Int. J. Rheum. Dis. 2021, 24, 159-169. [CrossRef] [PubMed]

9. Cañas, J.A.; Sastre, B.; Rodrigo-Muñoz, J.M.; del Pozo, V. Exosomes: A new approach to asthma pathology. Clin. Chim. Acta 2019, 495, 139-147. [CrossRef]

10. Wang, L.; Zhang, L. Circulating Exosomal miRNA as Diagnostic Biomarkers of Neurodegenerative Diseases. Front. Mol. Neurosci. 2020, 13, 53. [CrossRef]

11. Kalluri, R.; LeBleu, V.S. The biology, function, and biomedical applications of exosomes. Science 2020, 367. [CrossRef]

12. Lin, J.; Li, J.; Huang, B.; Liu, J.; Chen, X.; Chen, X.-M.; Xu, Y.-M.; Huang, L.-F.; Wang, X.-Z. Exosomes: Novel Biomarkers for Clinical Diagnosis. Sci. World J. 2015, 2015, 1-8. [CrossRef]

13. Cooper, J.M.; Wiklander, P.B.O.; Nordin, J.Z.; Al-Shawi, R.; Wood, M.J.; Vithlani, M.; Schapira, A.H.V.; Simons, J.P.; El-Andaloussi, S.; Alvarez-Erviti, L. Systemic exosomal siRNA delivery reduced alpha-synuclein aggregates in brains of transgenic mice. Mov. Disord. 2014, 29, 1476-1485. [CrossRef]

14. van Niel, G.; Charrin, S.; Simoes, S.; Romao, M.; Rochin, L.; Saftig, P.; Marks, M.S.; Rubinstein, E.; Raposo, G. The Tetraspanin CD63 Regulates ESCRT-Independent and -Dependent Endosomal Sorting during Melanogenesis. Dev. Cell 2011, $21,708-721$. [CrossRef]

15. Conde-Vancells, J.; Rodriguez-Suarez, E.; Embade, N.; Gil, D.; Matthiesen, R.; Valle, M.; Elortza, F.; Lu, S.C.; Mato, J.M.; FalconPerez, J.M. Characterization and Comprehensive Proteome Profiling of Exosomes Secreted by Hepatocytes. J. Proteome Res. 2008, 7, 5157-5166. [CrossRef] 
16. Subra, C.; Grand, D.; Laulagnier, K.; Stella, A.; Lambeau, G.; Paillasse, M.; De Medina, P.; Monsarrat, B.; Perret, B.; Silvente-Poirot, S.; et al. Exosomes account for vesicle-mediated transcellular transport of activatable phospholipases and prostaglandins. J. Lipid Res. 2010, 51, 2105-2120. [CrossRef] [PubMed]

17. Witas, R.; Chaput, D.; Khan, H.; Stevens, S.M.; Kang, D. Isolation and Proteomic Analysis of Microvesicles and Exosomes from HT22 Cells and Primary Neurons. In Neuroproteomics; Humana Press: New York, NY, USA, 2017; pp. $255-267$.

18. Liang, B.; Peng, P.; Chen, S.; Li, L.; Zhang, M.; Cao, D.; Yang, J.; Li, H.; Gui, T.; Li, X.; et al. Characterization and proteomic analysis of ovarian cancer-derived exosomes. J. Proteom. 2013, 80, 171-182. [CrossRef]

19. Théry, C.; Zitvogel, L.; Amigorena, S. Exosomes: Composition, biogenesis and function. Nat. Rev. Immunol. 2002, 2, 569-579. [CrossRef]

20. Farooqi, A.A.; Desai, N.N.; Qureshi, M.Z.; Librelotto, D.R.N.; Gasparri, M.L.; Bishayee, A.; Nabavi, S.M.; Curti, V.; Daglia, M. Exosome biogenesis, bioactivities and functions as new delivery systems of natural compounds. Biotechnol. Adv. 2018, 36, 328-334. [CrossRef]

21. Lin, S.; Yu, Z.; Chen, D.; Wang, Z.; Miao, J.; Li, Q.; Zhang, D.; Song, J.; Cui, D. Progress in Microfluidics-Based Exosome Separation and Detection Technologies for Diagnostic Applications. Small 2020, 16, 1903916. [CrossRef] [PubMed]

22. Doyle, L.; Wang, M. Overview of Extracellular Vesicles, Their Origin, Composition, Purpose, and Methods for Exosome Isolation and Analysis. Cells 2019, 8, 727. [CrossRef] [PubMed]

23. Morita, E.; Sandrin, V.; Chung, H.-Y.; Morham, S.G.; Gygi, S.P.; Rodesch, C.K.; Sundquist, W.I. Human ESCRT and ALIX proteins interact with proteins of the midbody and function in cytokinesis. EMBO J. 2007, 26, 4215-4227. [CrossRef] [PubMed]

24. Géminard, C.; de Gassart, A.; Blanc, L.; Vidal, M. Degradation of AP2 During Reticulocyte Maturation Enhances Binding of Hsc70 and Alix to a Common Site on TfR for Sorting into Exosomes. Traffic 2004, 5, 181-193. [CrossRef] [PubMed]

25. Witwer, K.W.; Buzás, E.I.; Bemis, L.T.; Bora, A.; Lässer, C.; Lötvall, J.; Nolte-`t Hoen, E.N.; Piper, M.G.; Sivaraman, S.; Skog, J.; et al. Standardization of sample collection, isolation and analysis methods in extracellular vesicle research. J. Extracell. Vesicles 2013, 2, 20360. [CrossRef]

26. Crescitelli, R.; Lässer, C.; Szabó, T.G.; Kittel, A.; Eldh, M.; Dianzani, I.; Buzás, E.I.; Lötvall, J. Distinct RNA profiles in subpopulations of extracellular vesicles: Apoptotic bodies, microvesicles and exosomes. J. Extracell. Vesicles 2013, 2, 20677. [CrossRef] [PubMed]

27. Bullock, M.; Silva, A.; Kanlikilicer-Unaldi, P.; Filant, J.; Rashed, M.; Sood, A.; Lopez-Berestein, G.; Calin, G. Exosomal Non-Coding RNAs: Diagnostic, Prognostic and Therapeutic Applications in Cancer. Non-Coding RNA 2015, 1, 53-68. [CrossRef] [PubMed]

28. Nahand, J.S.; Mahjoubin-Tehran, M.; Moghoofei, M.; Pourhanifeh, M.H.; Mirzaei, H.R.; Asemi, Z.; Khatami, A.; Bokharaei-Salim, F.; Mirzaei, H.; Hamblin, M.R. Exosomal miRNAs: Novel players in viral infection. Epigenomics 2020, 12, 353-370. [CrossRef] [PubMed]

29. Mao, L.; Li, X.; Gong, S.; Yuan, H.; Jiang, Y.; Huang, W.; Sun, X.; Dang, X. Serum exosomes contain ECRG4 mRNA that suppresses tumor growth via inhibition of genes involved in inflammation, cell proliferation, and angiogenesis. Cancer Gene Ther. 2018, 25, 248-259. [CrossRef]

30. Zhang, Y.; Cai, F.; Liu, J.; Chang, H.; Liu, L.; Yang, A.; Liu, X. Transfer RNA-derived fragments as potential exosome tRNA-derived fragment biomarkers for osteoporosis. Int. J. Rheum. Dis. 2018, 21, 1659-1669. [CrossRef]

31. Möhrmann, L.; Huang, H.J.; Hong, D.S.; Tsimberidou, A.M.; Fu, S.; Piha-Paul, S.A.; Subbiah, V.; Karp, D.D.; Naing, A.; Krug, A.; et al. Liquid Biopsies Using Plasma Exosomal Nucleic Acids and Plasma Cell-Free DNA Compared with Clinical Outcomes of Patients with Advanced Cancers. Clin. Cancer Res. 2018, 24, 181-188. [CrossRef] [PubMed]

32. Tellez-Gabriel, M.; Knutsen, E.; Perander, M. Current Status of Circulating Tumor Cells, Circulating Tumor DNA, and Exosomes in Breast Cancer Liquid Biopsies. Int. J. Mol. Sci. 2020, 21, 9457. [CrossRef]

33. Record, M.; Silvente-Poirot, S.; Poirot, M.; Wakelam, M.O. Extracellular vesicles: Lipids as key components of their biogenesis and functions. J. Lipid Res. 2018, 59, 1316-1324. [CrossRef]

34. Skotland, T.; Hessvik, N.P.; Sandvig, K.; Llorente, A. Exosomal lipid composition and the role of ether lipids and phosphoinositides in exosome biology. J. Lipid Res. 2019, 60, 9-18. [CrossRef] [PubMed]

35. Iliescu, F.; Vrtačnik, D.; Neuzil, P.; Iliescu, C. Microfluidic Technology for Clinical Applications of Exosomes. Micromachines 2019, 10, 392. [CrossRef]

36. Bennit, H.R.F.; Gonda, A.; McMullen, J.R.W.; Kabagwira, J.; Wall, N.R. Peripheral Blood Cell Interactions of Cancer-Derived Exosomes Affect Immune Function. Cancer Microenviron. 2019, 12, 29-35. [CrossRef] [PubMed]

37. Kong, F.-L.; Wang, X.-P.; Li, Y.-N.; Wang, H.-X. The role of exosomes derived from cerebrospinal fluid of spinal cord injury in neuron proliferation in vitro. Artif. Cells Nanomed. Biotechnol. 2018, 46, 200-205. [CrossRef]

38. Hou, R.; Li, Y.; Sui, Z.; Yuan, H.; Yang, K.; Liang, Z.; Zhang, L.; Zhang, Y. Advances in exosome isolation methods and their applications in proteomic analysis of biological samples. Anal. Bioanal. Chem. 2019, 411, 5351-5361. [CrossRef]

39. Klingeborn, M.; Skiba, N.P.; Stamer, W.D.; Rickman, C.B. Isolation of Retinal Exosome Biomarkers from Blood by Targeted Immunocapture. In Retinal Degenerative Diseases; Springer: Berlin, Germany, 2019; pp. 21-25.

40. Sharma, P.; Ludwig, S.; Muller, L.; Hong, C.S.; Kirkwood, J.M.; Ferrone, S.; Whiteside, T.L. Immunoaffinity-based isolation of melanoma cell-derived exosomes from plasma of patients with melanoma. J. Extracell. Vesicles 2018, 7, 1435138. [CrossRef] [PubMed] 
41. Cui, B.; Liu, C.; Yao, S. One-Step RT-PCR for Detection of Micrornas in Exosomes Using Droplet Microfluidics. In Proceedings of the 2020 IEEE 33rd International Conference on Micro Electro Mechanical Systems (MEMS), Vancouver, BC, Canada, 18-20 January 2020; pp. 142-146.

42. Nwokwu, C.D.; Bari, S.M.I.; Hutson, K.H.; Brausell, C.; Nestorova, G.G. ExoPRIME: Solid-phase immunoisolation and OMICS analysis of surface-marker-specific exosomal subpopulations. Talanta 2022, 236, 122870. [CrossRef]

43. Guerreiro, E.M.; Vestad, B.; Steffensen, L.A.; Aass, H.C.D.; Saeed, M.; Øvstebø, R.; Costea, D.E.; Galtung, H.K.; Søland, T.M. Efficient extracellular vesicle isolation by combining cell media modifications, ultrafiltration, and size-exclusion chromatography. PLoS ONE 2018, 13, e0204276. [CrossRef]

44. Mitchell, M.D. Exosome enrichment by ultracentrifugation and size exclusion chromatography. Front. Biosci. $2018,23,4621$. [CrossRef]

45. Contreras-Naranjo, J.C.; Wu, H.-J.; Ugaz, V.M. Microfluidics for exosome isolation and analysis: Enabling liquid biopsy for personalized medicine. Lab Chip 2017, 17, 3558-3577. [CrossRef] [PubMed]

46. Greening, D.W.; Xu, R.; Ji, H.; Tauro, B.J.; Simpson, R.J. A Protocol for Exosome Isolation and Characterization: Evaluation of Ultracentrifugation, Density-Gradient Separation, and Immunoaffinity Capture Methods. In Proteomic Profiling; Humana Press: New York, NY, USA, 2015; pp. 179-209.

47. Lobb, R.; Möller, A. Size Exclusion Chromatography: A Simple and Reliable Method for Exosome Purification. In Extracellular Vesicles; Humana Press: New York, NY, USA, 2017; pp. 105-110.

48. Navajas, R.; Corrales, F.J.; Paradela, A. Serum Exosome Isolation by Size-Exclusion Chromatography for the Discovery and Validation of Preeclampsia-Associated Biomarkers. In Proteomics for Biomarker Discovery; Humana Press: New York, NY, USA, 2019; pp. 39-50.

49. Soares Martins, T.; Catita, J.; Martins Rosa, I.; Odete, A.B.; da Cruz e Silva, O.; Henriques, A.G. Exosome isolation from distinct biofluids using precipitation and column-based approaches. PLoS ONE 2018, 13, e0198820. [CrossRef] [PubMed]

50. Xiao, D.; Ohlendorf, J.; Chen, Y.; Taylor, D.D.; Rai, S.N.; Waigel, S.; Zacharias, W.; Hao, H.; McMasters, K.M. Identifying mRNA, MicroRNA and Protein Profiles of Melanoma Exosomes. PLoS ONE 2012, 7, e46874. [CrossRef]

51. Alvarez, M.L.; Khosroheidari, M.; Kanchi Ravi, R.; DiStefano, J.K. Comparison of protein, microRNA, and mRNA yields using different methods of urinary exosome isolation for the discovery of kidney disease biomarkers. Kidney Int. 2012, 82, 1024-1032. [CrossRef]

52. He, L.; Zhu, D.; Wang, J.; Wu, X. A highly efficient method for isolating urinary exosomes. Int. J. Mol. Med. 2018, 43, 83-90. [CrossRef] [PubMed]

53. Theodoraki, M.; Hong, C.; Donnenberg, V.S.; Donnenberg, A.D.; Whiteside, T.L. Evaluation of Exosome Proteins by on-Bead Flow Cytometry. Cytom. Part A 2021, 99, 372-381. [CrossRef]

54. van der Vlist, E.J.; Nolte-'t Hoen, E.N.M.; Stoorvogel, W.; Arkesteijn, G.J.A.; Wauben, M.H.M. Fluorescent labeling of nano-sized vesicles released by cells and subsequent quantitative and qualitative analysis by high-resolution flow cytometry. Nat. Protoc. 2012, 7, 1311-1326. [CrossRef] [PubMed]

55. Serrano-Pertierra, E.; Oliveira-Rodríguez, M.; Matos, M.; Gutiérrez, G.; Moyano, A.; Salvador, M.; Rivas, M.; Blanco-López, M.C. Extracellular Vesicles: Current Analytical Techniques for Detection and Quantification. Biomolecules 2020, 10, 824. [CrossRef]

56. Wang, C.; Ding, Q.; Plant, P.; Basheer, M.; Yang, C.; Tawedrous, E.; Krizova, A.; Boulos, C.; Farag, M.; Cheng, Y.; et al. Droplet digital PCR improves urinary exosomal miRNA detection compared to real-time PCR. Clin. Biochem. 2019, 67, 54-59. [CrossRef]

57. Cho, S.M.; Shin, S.; Kim, Y.; Song, W.; Hong, S.G.; Jeong, S.H.; Kang, M.S.; Lee, K.A. A novel approach for tuberculosis diagnosis using exosomal DNA and droplet digital PCR. Clin. Microbiol. Infect. 2020, 26, e1-e942. [CrossRef]

58. Anderson, W.; Lane, R.; Korbie, D.; Trau, M. Observations of Tunable Resistive Pulse Sensing for Exosome Analysis: Improving System Sensitivity and Stability. Langmuir 2015, 31, 6577-6587. [CrossRef] [PubMed]

59. Yamauchi, M.; Shimizu, K.; Rahman, M.; Ishikawa, H.; Takase, H.; Ugawa, S.; Okada, A.; Inoshima, Y. Efficient method for isolation of exosomes from raw bovine milk. Drug Dev. Ind. Pharm. 2019, 45, 359-364. [CrossRef] [PubMed]

60. Dou, D.; Ren, X.; Han, M.; Xu, X.; Ge, X.; Gu, Y.; Wang, X. Cancer-Associated Fibroblasts-Derived Exosomes Suppress Immune Cell Function in Breast Cancer via the miR-92/PD-L1 Pathway. Front. Immunol. 2020, 11, 2026. [CrossRef]

61. Liu, C.; Guo, J.; Tian, F.; Yang, N.; Yan, F.; Ding, Y.; Wei, J.; Hu, G.; Nie, G.; Sun, J. Field-Free Isolation of Exosomes from Extracellular Vesicles by Microfluidic Viscoelastic Flows. ACS Nano 2017, 11, 6968-6976. [CrossRef]

62. Gaillard, M.; Thuaire, A.; Nonglaton, G.; Agache, V.; Roupioz, Y.; Raillon, C. Biosensing extracellular vesicles: Contribution of biomolecules in affinity-based methods for detection and isolation. Analyst 2020, 145, 1997-2013. [CrossRef] [PubMed]

63. Gurunathan, S.; Kang, M.-H.; Jeyaraj, M.; Qasim, M.; Kim, J.-H. Review of the Isolation, Characterization, Biological Function, and Multifarious Therapeutic Approaches of Exosomes. Cells 2019, 8, 307. [CrossRef]

64. Wang, W.; Wu, C.; Jin, H. Exosomes in chronic inflammatory skin diseases and skin tumors. Exp. Dermatol. 2019, 28, 213-218. [CrossRef]

65. Wang, J.; Ma, P.; Kim, D.H.; Liu, B.-F.; Demirci, U. Towards microfluidic-based exosome isolation and detection for tumor therapy. Nano Today 2021, 37, 101066. [CrossRef]

66. Le, M.-C.N.; Fan, H.Z. Exosome isolation using nanostructures and microfluidic devices. Biomed. Mater. 2021, 16. [CrossRef] 
67. Lin, B.; Lei, Y.; Wang, J.; Zhu, L.; Wu, Y.; Zhang, H.; Wu, L.; Zhang, P.; Yang, C. Micro fluidic-Based Exosome Analysis for Liquid Biopsy. Small Methods 2021, 5, 2001131. [CrossRef]

68. Zhang, H.; Freitas, D.; Kim, H.S.; Fabijanic, K.; Li, Z.; Chen, H.; Mark, M.T.; Molina, H.; Martin, A.B.; Bojmar, L.; et al. Identification of distinct nanoparticles and subsets of extracellular vesicles by asymmetric flow field-flow fractionation. Nat. Cell Biol. 2018, 20, 332-343. [CrossRef] [PubMed]

69. Liu, F.; Vermesh, O.; Mani, V.; Ge, T.J.; Madsen, S.J.; Sabour, A.; Hsu, E.-C.; Gowrishankar, G.; Kanada, M.; Jokerst, J.V.; et al. The Exosome Total Isolation Chip. ACS Nano 2017, 11, 10712-10723. [CrossRef]

70. Woo, H.-K.; Sunkara, V.; Park, J.; Kim, T.-H.; Han, J.-R.; Kim, C.-J.; Choi, H.-I.; Kim, Y.-K.; Cho, Y.-K. Exodisc for Rapid, SizeSelective, and Efficient Isolation and Analysis of Nanoscale Extracellular Vesicles from Biological Samples. ACS Nano 2017, 11, 1360-1370. [CrossRef]

71. Yasui, T.; Yanagida, T.; Ito, S.; Konakade, Y.; Takeshita, D.; Naganawa, T.; Nagashima, K.; Shimada, T.; Kaji, N.; Nakamura, Y.; et al. Unveiling massive numbers of cancer-related urinary-microRNA candidates via nanowires. Sci. Adv. 2017, 3, e1701133. [CrossRef] [PubMed]

72. Chen, Z.; Yang, Y.; Yamaguchi, H.; Hung, M.-C.; Kameoka, J. Isolation of cancer-derived extracellular vesicle subpopulations by a size-selective microfluidic platform. Biomicrofluidics 2020, 14, 034113. [CrossRef] [PubMed]

73. Kanwar, S.S.; Dunlay, C.J.; Simeone, D.M.; Nagrath, S. Microfluidic device (ExoChip) for on-chip isolation, quantification and characterization of circulating exosomes. Lab Chip 2014, 14, 1891-1900. [CrossRef] [PubMed]

74. Li, B.; Pan, W.; Liu, C.; Guo, J.; Shen, J.; Feng, J.; Luo, T.; Situ, B.; Zhang, Y.; An, T.; et al. Homogenous Magneto-Fluorescent Nanosensor for Tumor-Derived Exosome Isolation and Analysis. ACS Sens. 2020, 5, 2052-2060. [CrossRef] [PubMed]

75. Han, J.; Zhang, L.; Cui, M.; Su, Y.; He, Y. Rapid and Accurate Detection of Lymph Node Metastases Enabled through Fluorescent Silicon Nanoparticles-Based Exosome Probes. Anal. Chem. 2021, 93, 10122-10131. [CrossRef] [PubMed]

76. Vaidyanathan, R.; Naghibosadat, M.; Rauf, S.; Korbie, D.; Carrascosa, L.G.; Shiddiky, M.J.A.; Trau, M. Detecting Exosomes Specifically: A Multiplexed Device Based on Alternating Current Electrohydrodynamic Induced Nanoshearing. Anal. Chem. 2014, 86, 11125-11132. [CrossRef]

77. Xu, L.; Chopdat, R.; Li, D.; Al-Jamal, K.T. Development of a simple, sensitive and selective colorimetric aptasensor for the detection of cancer-derived exosomes. Biosens. Bioelectron. 2020, 169, 112576. [CrossRef]

78. Zhang, Y.; Jiao, J.; Wei, Y.; Wang, D.; Yang, C.; Xu, Z. Plasmonic Colorimetric Biosensor for Sensitive Exosome Detection via Enzyme-Induced Etching of Gold Nanobipyramid@MnO 2 Nanosheet Nanostructures. Anal. Chem. 2020, 92, 15244-15252. [CrossRef]

79. Issadore, D.; Min, C.; Liong, M.; Chung, J.; Weissleder, R.; Lee, H. Miniature magnetic resonance system for point-of-care diagnostics. Lab Chip 2011, 11, 2282. [CrossRef]

80. Shao, H.; Chung, J.; Balaj, L.; Charest, A.; Bigner, D.D.; Carter, B.S.; Hochberg, F.H.; Breakefield, X.O.; Weissleder, R.; Lee, H. Protein typing of circulating microvesicles allows real-time monitoring of glioblastoma therapy. Nat. Med. 2012, 18, 1835-1840. [CrossRef]

81. Sancho-Albero, M.; Sebastián, V.; Sesé, J.; Pazo-Cid, R.; Mendoza, G.; Arruebo, M.; Martín-Duque, P.; Santamaría, J. Isolation of exosomes from whole blood by a new microfluidic device: Proof of concept application in the diagnosis and monitoring of pancreatic cancer. J. Nanobiotechnol. 2020, 18, 150. [CrossRef]

82. de Almeida, M.P.; Pereira, E.; Baptista, P.; Gomes, I.; Figueiredo, S.; Soares, L.; Franco, R. Gold Nanoparticles as (Bio) Chemical Sensors. Comp. Anal. Chem. 2014, 66, 529-567.

83. Zeng, S.; Baillargeat, D.; Ho, H.-P.; Yong, K.-T. Nanomaterials enhanced surface plasmon resonance for biological and chemical sensing applications. Chem. Soc. Rev. 2014, 43, 3426. [CrossRef] [PubMed]

84. Zhu, L.; Wang, K.; Cui, J.; Liu, H.; Bu, X.; Ma, H.; Wang, W.; Gong, H.; Lausted, C.; Hood, L.; et al. Label-Free Quantitative Detection of Tumor-Derived Exosomes through Surface Plasmon Resonance Imaging. Anal. Chem. 2014, 86, 8857-8864. [CrossRef]

85. Chen, W.; Li, J.; Wei, X.; Fan, Y.; Qian, H.; Li, S.; Xiang, Y.; Ding, S. Surface plasmon resonance biosensor using hydrogel-AuNP supramolecular spheres for determination of prostate cancer-derived exosomes. Microchim. Acta 2020, 187, 590. [CrossRef] [PubMed]

86. Xu, L.; Shoaie, N.; Jahanpeyma, F.; Zhao, J.; Azimzadeh, M.; Al-Jamal, K.T. Optical, electrochemical and electrical (nano)biosensors for detection of exosomes: A comprehensive overview. Biosens. Bioelectron. 2020, 161, 112222. [CrossRef] [PubMed]

87. Zhou, Q.; Rahimian, A.; Son, K.; Shin, D.-S.; Patel, T.; Revzin, A. Development of an aptasensor for electrochemical detection of exosomes. Methods 2016, 97, 88-93. [CrossRef] [PubMed]

88. Kashefi-Kheyrabadi, L.; Kim, J.; Chakravarty, S.; Park, S.; Gwak, H.; Kim, S.-I.; Mohammadniaei, M.; Lee, M.-H.; Hyun, K.-A.; Jung, H.-I. Detachable microfluidic device implemented with electrochemical aptasensor (DeMEA) for sequential analysis of cancerous exosomes. Biosens. Bioelectron. 2020, 169, 112622. [CrossRef] [PubMed]

89. Chen, C.; Skog, J.; Hsu, C.-H.; Lessard, R.T.; Balaj, L.; Wurdinger, T.; Carter, B.S.; Breakefield, X.O.; Toner, M.; Irimia, D. Microfluidic isolation and transcriptome analysis of serum microvesicles. Lab Chip 2010, 10, 505-511. [CrossRef]

90. Zhang, P.; He, M.; Zeng, Y. Ultrasensitive microfluidic analysis of circulating exosomes using a nanostructured graphene oxide/polydopamine coating. Lab Chip 2016, 16, 3033-3042. [CrossRef] [PubMed] 
91. Zhang, Y.; Tong, X.; Yang, L.; Yin, R.; Li, Y.; Zeng, D.; Wang, X.; Deng, K. A herringbone mixer based microfluidic device HBEXO-chip for purifying tumor-derived exosomes and establishing miRNA signature in pancreatic cancer. Sens. Actuators $B$ Chem. 2021, 332, 129511. [CrossRef]

92. Ishraq Bari, S.M.; Reis, L.G.; Holland, T.; Nestorova, G.G. Numerical analysis of optimal design parameters for a cell co-culture microfluidic platform with an integrated pressure-controlled valve. In Proceedings of the ASME International Mechanical Engineering Congress and Exposition, Online, 16-19 November 2020.

93. Xu, H.; Liao, C.; Zuo, P.; Liu, Z.; Ye, B.-C. Magnetic-Based Microfluidic Device for On-Chip Isolation and Detection of TumorDerived Exosomes. Anal. Chem. 2018, 90, 13451-13458. [CrossRef] [PubMed] 